\title{
Review: The role of human-related risk in breeding site selection by wolves
}

Víctor Sazatornil ${ }^{1}$, Alejandro Rodríguez ${ }^{2}$, Michael Klaczek ${ }^{3}$, Mohsen Ahmadi ${ }^{4}$, Francisco Álvares ${ }^{5}$, Stephen Arthur ${ }^{6}$, Juan Carlos Blanco ${ }^{7}$, Bridget L. Borg ${ }^{6}$, Dean Cluff $^{8}$, Yolanda Cortés ${ }^{7}$, Emilio J. García ${ }^{9}$, Eli Geffen ${ }^{10}$, Bilal Habib ${ }^{11}$, Yorgos Iliopoulos ${ }^{12}$, Mohammad Kaboli $^{13}$, Miha Krofel $^{14}$, Luis Llaneza ${ }^{9}$, Francesca Marucco $^{15}$, John K. Oakleaf ${ }^{16}$, David K. Person ${ }^{17}$, Hubert Potočnik ${ }^{14}$, Nina Ražen ${ }^{14}$, Helena Rio-Maior ${ }^{5}$, Håkan Sand ${ }^{18}$, David Unger ${ }^{19}$, Petter Wabakken ${ }^{20}$ and José Vicente López-Bao ${ }^{18,21 *}$

${ }^{1}$ Department of Animal Biology, University of Barcelona. Av. Diagonal, 643, 08028 Barcelona, Spain. ${ }^{2}$ Department of Conservation Biology, Estación Biológica de Doñana, CSIC, Américo Vespucio s/n, 41092 Sevilla, Spain.

${ }^{3}$ Natural Resources and Environmental Studies Graduate Program, University of Northern British Columbia. 3333 University Way Prince George, BC, Canada

${ }^{4}$ Department of Natural Resources, Isfahan University of Technology, Isfahan, Iran

${ }^{5}$ CIBIO/InBio, Centro de Investigação em Biodiversidade e Recursos Genéticos, Universidade do Porto, 4485-661 Vairão, Portugal.

${ }^{6}$ National Park Service, Denali National Park and Preserve, P.O. Box 9, Denali Park, AK 99755, USA

${ }^{7}$ Wolf Project, Consultores en Biología de la Conservación, Calle Manuela Malasana 24, 28004 Madrid, Spain.

${ }^{8}$ Department of Environment and Natural Resources, North Slave Region, Government of the Northwest Territories, P.O. Box 2668, 3803 Bretzlaff Drive., Yellowknife, Northwest Territories X1A 2P9, Canada.

${ }^{9}$ A.RE.NA. Asesores en Recursos Naturales, S.L., Lugo, Spain.

${ }^{10}$ Department of Zoology, Tel Aviv University Tel Aviv 69978 Israel.

${ }^{11}$ Department of Animal Ecology and Conservation Biology, Wildlife Institute of India, India

${ }^{12}$ Department of Zoology, School of Biology, Aristotle University of Thessaloniki, 54124 Thessaloniki,

Greece.

${ }^{13}$ Department of Environmental Sciences, Faculty of Natural Resources, University of Tehran, Karaj, Iran

${ }^{14}$ University of Ljubljana, Biotechnical Faculty, Jamnikarjeva 101, 1000 Ljubljana, Slovenia. 
${ }^{15}$ Centro Gestione e Conservazione Grandi Carnivori,Parco Naturale Alpi Maritime, Piazza Regina Elena 30, Valdieri 12010, Italy.

${ }^{16}$ U.S. Fish and Wildlife Service, Mexican Wolf Program, 2105 Osuna Road, NE, Albuquerque, NM 87113, USA.

${ }^{17} 482$ Murphy Road, Braintree, Vermont 05060, USA.

${ }^{18}$ Grimsö Wildlife Research Station, Department of Ecology, Swedish University of Agricultural Sciences, 73091 Riddarhyttan, Sweden.

${ }^{19}$ Biology Department, Maryville College, Maryville, TN 37804, USA.

${ }^{20}$ Hedmark University College, Evenstad, 2480 Koppang, Norway.

${ }^{21}$ Research Unit of Biodiversity (UO/ CSIC/PA), Oviedo University, 33600 Mieres, Spain.

* Corresponding author: José Vicente López-Bao (jv.lopezbao@gmail.com)

Keywords: homesites, large carnivores, human-dominated landscapes, continental patterns, human-made structures, human population density, persistence, persecution.

\section{Abstract}

Large carnivores can be found in different scenarios of cohabitation with humans. Behavioral adaptations to minimize risk from humans are expected to be exacerbated where large carnivores are most vulnerable, such as at breeding sites. Using wolves as a model species, along with data from 26 study areas across the species' ${ }^{\prime}$ worldwide range, we performed a meta-analysis to assess the role of humans in breeding site selection by a large carnivore. Some of the patterns previously observed at the local scale become extrapolatable to the entire species range provided that important sources of variation are taken into account. Generally, wolves minimised the risk of exposure at breeding sites by avoiding human-made structures, selecting shelter from vegetation and avoiding agricultural lands. Our results suggest a scaled hierarchical habitat selection process across selection orders by which wolves compensate higher exposure risk to humans within their territories via a stronger selection at breeding 
sites. Dissimilar patterns between continents suggest that adaptations to cope with human-associated risks are modulated by the history of coexistence and persecution. Although many large carnivores persisting in human-dominated landscapes do not require large-scale habitat preservation, habitat selection at levels below occupancy and territory should be regarded in management and conservation strategies aiming to preserve these species in such contexts. In this case, we recommend providing shelter from human interference at least in small portions of land in order to fulfill the requirements of the species to locate their breeding sites.

\section{Introduction}

Despite the fact that large carnivores are focal species for biodiversity conservation their predatory behaviour leads to their persecution (both legal hunting and poaching) worldwide. Different perceptions and interests contribute to controversy on their conservation and management, including whether or how to coexist with these species (Packer et al., 2013; Chapron et al., 2014). Mitigating conflicts and promoting coexistence have become cornerstones of large carnivore conservation in modern times. Consequently, a comprehensive knowledge of the different human and carnivore factors that make coexistence possible is required. Understanding the adaptive behaviours of large carnivores favouring their persistence in humandominated landscapes is pivotal for delineating effective conservation measures.

Apart from persecution, sharing the landscape has traditionally driven both humans and large carnivores to adopt adaptive strategies in order to coexist. While humans have historically implemented damage prevention measures (e.g., livestock guarding dogs, shepherds, enclosures; Woodroffe et al., 2007; Linnell et al., 2012), large carnivores have adopted different behavioural adaptations to minimise risks 
(e.g., temporal or fine-scale spatial segregation; Theuerkauf et al., 2003; Habib and Kumar, 2007; Zedrosser et al., 2011; Ahmadi et al., 2014). On a global scale, historical and human determinants seem to lie behind dissimilar outcomes in such competitive scenarios given, for instance, the persistence of large carnivores in densely populated landscapes in Europe as compared to their absence in similarly populated regions of North America (Chapron et al., 2014).

Many large carnivore populations can be found outside of protected areas and can breed and thrive in human-dominated landscapes with few or negligible portions of natural habitats (Abay et al., 2011; Athreya et al., 2013; Ahmadi et al., 2014; López-Bao et al., 2015). Wolves (Canis lupus) are the most widely distributed large carnivore species with which humans share the landscape (Mech and Boitani, 2003). However, coexistence is largely variable in terms of interaction attributes and conflict intensity (e.g., Agarwala and Kumar, 2009; López-Bao et al., 2013; Chapron et al., 2014). Wolves are resilient and able to thrive under a wide spectrum of biotic and abiotic conditions (Mech and Boitani, 2003). As a consequence, they have traditionally been considered habitat generalists, being habitat tolerance mainly shaped by food availability and mortality risk (Mech and Boitani, 2003). Such constraining factors of habitat tolerance are the same for most large carnivore species (Woodroffe and Ginsberg, 1998; Fuller and Sievert, 2001). Therefore, wolves are a good model species for gaining a better understanding of the behavioural adaptations of large carnivores to humans.

Human impacts (e.g., persecution, disturbance) result in different behavioural responses of large carnivores, such as wolves, to minimise their interactions with humans and their effects (e.g., Whittington et al., 2005; Llaneza et al., 2012; Lesmerises et al., 2013; Ahmadi et al., 2014). Factors influencing exposure risk, such 
as the availability of refuge habitat, are also modulated by human activity and impact at the landscape level (Thurber et al., 1994; Llaneza et al., 2012). During the pup rearing season, when large carnivores are more vulnerable, these species are expected to strengthen avoidance behaviour from humans.

In the case of wolves, during the breeding period (April - early autumn in temperate regions; Mech, 1970; Carbyn et al., 1993), pack members, especially the breeding female and the pups, become temporally and spatially predictable (Ruprecht et al., 2012) around den and rendezvous sites (known together as homesites; Joslin, 1967). This predictability increases their exposure risk. Wolves are known to compensate for their intrinsic vulnerability during this period by selecting areas with low human activity or adjusting their temporal use in response to human activities (Theuerkauf et al., 2003; Capitani et al., 2006; Habib and Kumar, 2007; Person and Russell, 2009; Ahmadi et al., 2014; Iliopoulos et al., 2014; but see Mech et al., 1988; Thiel et al., 1998). However, the constancy and generality of the behavioural adaptations of wolves to humans remain unclear (e.g., available literature shows contrasting patterns on the influence of roads on wolf behaviour; Thiel, 1985; Mech, 1989; Thurber et al., 1994; Jędrzejewski et al., 2004; Whittington et al., 2005; Zimmermann et al., 2014).

Herein, we explored how perceived exposure risk to humans affects the selection patterns of breeding sites in wolves. By gathering wolves' homesite data across its worldwide distribution range (Fig. 1), we compiled the most comprehensive dataset to date about the breeding site selection patterns of a large carnivore on a global scale. The large distribution range of wolves is comprised by a wide arrange of local environmental constraints for the species. Such heterogeneity poses a risk of misleading generalisation on the general behavioural response of wolves to humans 
from context-specific observations (Levin, 1992). Therefore, we sought to decontextualise the general patterns of homesite selection by wolves through a metaanalysis.

First, we hypothesised a global common pattern in the signal of the behavioural response of wolves towards the same source of mortality risk and disturbance, humans. We assessed whether the direction and magnitude of selection in relation to vulnerability to humans coincided between den and rendezvous sites. Second, we hypothesised that the response to avoid human-related risk at homesites would be stronger where a longer history of coexistence has allowed wolves to adapt and persist under continued persecution. Accordingly, we expected to find continental-scale effects due to major differences in the coexistence nature between North America and Eurasia. For example, whereas it took many centuries to eliminate large carnivores from most of Western Europe, they were eradicated from most of the American West within a few decades (Frank and Woodroffe, 2001). Finally, we hypothesised that the strength of this behavioural response would be proportional to the intensity of context-specific, human-related, environmental constraints. We predicted that wolves that are more exposed to people (i.e. closely cohabiting with humans and/or using anthropogenic resources, such as livestock) should compensate human-related risk by being more averse to human activities, locating their homesites in less accessible areas and with higher availability of refuge. Identifying global patterns of homesite selection provides valuable information to develop transferrable tools to be applied in wolf and possibly other large carnivore conservation, conciliating the persistence of these species with human activities. 


\section{Material and methods}

We carried out a systematic literature review to compile published data on homesites and primary data sources to build a combined dataset of homesite characteristics in relation to 16 predefined variables (Table 1) associated to human impacts, refuge habitat and topographic attributes. We focused on the impact of perceived risk of mortality or disturbance at homesites. Our initial assumption was that avoidance of human-made structures and accessible areas would be a common response across the entire distribution range of the species.

\subsection{Systematic review and primary data}

Systematic review was carried out using search terms of the type "Canis lupus AND ["den" OR "homesite" OR "rendezvous"]", in Google Scholar (scholar.google.com) and Scopus (scopus.com) literature search databases. We also searched in the literature-cited sections of all retrieved articles. We retained only those studies from which basic statistics (mean and s.d.) were available for any of the variables of interest for this meta-analyses (Table 1), both for homesites and control groups. In exceptional cases, we contacted corresponding authors in order to get raw data. Data from 8 study areas were obtained from literature review (Fig. 1). In addition, we compiled original data from a total of 449 geo-referenced homesites distributed across 18 study areas (Fig.1; mean of 25 homesites per study area, s.d.=10.6, range 4-41).

All homesites were categorized as den or rendezvous sites. For primary data, we classified homesites depending on the estimated age of the pups (criterion also used in most published papers, Appendix A). Thus, we considered den sites those where the breeding female gave birth and kept the pups during the first 6 weeks of life. Den sites were determined by telemetry or direct observation of the den. Sites 
used by pups approximately between 6 weeks and 5 months of age were classified as rendezvous sites. Rendezvous sites were located by telemetry, direct observation of the pups and/or howling surveys (Capitani et al., 2006; Llaneza et al., 2014). We set a den cut-off at June $15^{\text {th }}$ if direct observation of the den was not possible. We considered rendezvous sites those sites used from June $15^{\text {th }}$ until October $31^{\text {st }}$ when original data were not obtained using direct observation (Theuerkauf et al., 2003; Mech and Boitani, 2003). Primary data only for den or rendezvous sites were available for nine and five areas, respectively, with both being available in four study areas (Fig.1). Den and rendezvous sites were geo-referenced in the field or calculated using the centre of the clusters of GPS-positions of collared wolves. We assumed that our method for locating homesites did not influence our results because we were not interested in micro-scale patterns of homesite selection.

From the systematic review, we used variable measurements for homesites and random locations derived directly from the studies. However, for primary data, we characterised homesites using available environmental datasets and geographical information sources (Appendix B). We considered two spatial resolutions for variables on land cover and terrain ruggedness, 100 and 900 ha around homesites (Table 1). When the mean value of a variable was 0 for homesites or control group it was excluded from the final dataset.

To prevent auto-correlation in our primary homesite dataset, when two homesite locations were separated by less than 2,500 $\mathrm{m}$ from each other, we randomly excluded one of them. In addition, when possible (date of use and pack identification was not always available), we selected only one location per homesite type per year for every pack. Control points were randomly generated within an estimated home range around homesites. Home-ranges were estimated from telemetry when possible 
(Slovenia, Sweden), or as a buffer around homesites covering an area of variable size according to home-range sizes described for the corresponding or neighbouring wolf populations $(\mathrm{n}=15)$ (Appendix $\mathrm{C}$; unpublished data). We generated three random points for each homesite. When both den and rendezvous sites were available in a study area, this procedure was carried out separately. We used ArcGIS 10.0 (ESRI Inc., Redlands, CA, USA) and Google Earth 5.0 (Google Inc., Mountain View, CA) to process all geographic information data. Information used to characterize homesites from primary data was generated using contemporary layers and dates were adjusted between homesites and the measurements of the indicators of human-related disturbance and mortality risks as much as possible using the "Historic images tools" of Google Earth.

Human-made infrastructures were assumed to represent human presence and pressure (Table1). Topographical variables were used as indicators for the accessibility of the homesites. Higher elevations, steeper slopes and rougher terrain around homesites were considered to reduce human access and to be positively correlated with remoteness. Refuge habitat around homesites was classified into four categories according to their ability to provide visual and physical protection to wolves (Table1). Although most agricultural land would fit into the definition of Open Areas, we considered Agriculture separately because such areas are often areas with higher levels of human activity. Refuge habitat included those vegetation types that provided protection by visual obstruction, as well as impeded access of people to homesites. Terrain Ruggedness and refuge habitat categories were measured at 100 and 900 ha around homesites (Table 1).

Variables of human-made structures and topography were also grouped into two factors named Direct Vulnerability and Topography (Table 1) according to our 
interpretation regarding wolves' exposure to humans. Direct Vulnerability represented the risk of human-caused disturbance and/or mortality, while Topography accounted for variables related with accessibility based on topographical features and terrain characteristics that potentially would facilitate or prevent wolf-human interactions. We used these factors to test if the selection was influenced by constraints at the study-area level.

\subsection{Data Analyses}

Within each study area, data on descriptive variables corresponding to homesites and random points were transformed to a measure of the specific response (direction and magnitude) of wolves towards the risk of interaction with humans. For each variable within each study area, we calculated Hedge's $g$ and its associated variance as an independent and comparable effect size estimate using the package "compute.es" in R (Del Re, 2013). For simplicity, coherence among variables, and illustrative purposes, we shifted the sign of the effect size in those variables representing distance to human-made infrastructures, with negative values representing avoidance.

We built an individual random-effects model for each variable and grouping factor, assuming heterogeneity among study areas beyond sampling error, and estimated the average effect size, variance and heterogeneity among the true effects (Koricheva et al., 2013). Models were adjusted weighting individual effect sizes, according to variance within study areas as a bias correction of the true effects in the set of study areas (Viechtbauer, 2010). Confidence intervals (95\%) of the mean effect size across study areas were calculated for every variable alone and grouped by factors. Those variables and factors that included zero in their $95 \%$ confidence intervals were considered as non-significant effects. Between-study area variance for 
each random-effects model was assessed calculating the statistic $T^{2}$ by the restricted maximum-likelihood estimator method (Viechtbauer, 2005). In addition, we calculated the statistic $I^{2}(\%)$ as a measure of the amount of variability in the effect size estimates that can be attributed to heterogeneity among the true effects. Individual random-effects models were constructed separately for all homesites indistinctly of their class as well as separated as den or rendezvous sites and were computed using the package "metaphor" in R (Viechtbauer, 2010).

In a second step, we analysed the relationship between the effect sizes estimated for the different indicators of human-related risk at the level of homesites and a moderator considering the continental level - representing different persecution histories - (two levels: America, Eurasia; Appendix D). We built a Generalized Linear Model (GLM) with Gaussian distribution errors and identity link function to evaluate the influence of the continent on the effect sizes (Hedge's $g$ ) of variables and factors.

Finally, to test whether the strength of the homesite selection patterns was proportional to the intensity of context-specific human-related environmental constraints, we explored the influence of three cofactors representing different human-related traits of the study areas (human population density, wolf diet and livestock biomass density). Within each study area, we accounted for variability in the ecological context in relation to humans, which will affect the strength of the selection patterns (effect size) by calculating: i) human population density (inhabitants/km²), ii) a categorical description of the predominant items in the diet of the wolf population (three levels: wild prey, livestock, or mix) and iii) an estimation of livestock biomass density $\left(\mathrm{kg} / \mathrm{km}^{2}\right)$ (Appendix D). We then built a set of GLMs with Gaussian distribution errors and identity link function to evaluate the influence of each moderator independently on the effect sizes (Hedge's g) of variables and factors. Due 
to limited sample size, we only ran individual univariate GLM models for each variable and factor to avoid overparameterizing our models. All analyses were carried out in the R software (R Core Team, 2014).

\section{Results}

We gathered data from 26 study areas, 10 in North America and 16 in Eurasia (Fig. 1, Appendix A). The overall dataset contained information from a total of 728 homesites (457 den sites and 271 rendezvous sites; mean number of homesites per study area ( \pm s.d.): $28 \pm 14$ ). On average, we obtained valid information of $10.0 \pm 5.4$ variables per study area.

In combination, significant effects were observed across study areas in homesite (joined), den and rendezvous site selection patterns by wolves (Figs. 2 and 3), indicating a consistent behavioural response of wolves towards human-related risk regardless of the local context. Wolves showed avoidance of human-made structures (Fig. 2); placing their homesites significantly further from linear infrastructures (allkind roads, main roads) and human settlements (settlements, villages) compared to random points. This avoidance tended to be stronger for main roads and villages than for all-kind roads and settlements (Fig. 2). The strength of the observed response towards these variables was stronger for rendezvous sites compared to den sites, although significant differences were only detected for the distance to settlements (Fig. 2). Variables associated with topography (Elevation, Slope, Terrain Ruggedness) did not show a consistent pattern. We detected a significant selection only to locate rendezvous sites at higher altitudes (Fig. 2). Individual univariate random-effects models for Elevation and Slope, including the all-class homesites dataset, retained a high amount of between-study heterogeneity representing $83 \%$ and $79 \%$ of the 
observed variability (Table 2). When we grouped the selected variables into factors, we found that Direct Vulnerability was negatively selected by wolves while Topography showed a pattern of selection only for rendezvous sites, towards the most inaccessible areas (Fig. 2).

Wolves located their homesites in areas with significantly higher availability of Refuge habitat, while avoided agricultural lands (Fig. 3); with these patterns being consistent across spatial resolutions regardless of homesite type (Fig. 3). Moreover, we found a general avoidance of Urban areas around homesites, although such a pattern was not significant when we evaluated den and rendezvous sites separately at the 100ha resolution (Fig. 3). No clear effect of Open Areas was observed (heterogeneity $T^{2}$ remained well below of the mean value -0.127 across all the variables; Table 2). We did not find significant differences between spatial resolutions regarding Refuge habitat or Terrain Ruggedness, suggesting non-independence in the observed patterns across the spatial resolutions considered (Fig. 3).

We detected a significant continental-scale pattern in homesite selection (Fig. 4) (Appendix E). We found significant differences in the selection of topographyrelated variables either alone (Elevation, Slope) or pooled as a factor (Topography) between continents (Appendix E and F). Topography was positively selected in Eurasia, indicating that wolves minimize exposure risk locating their homesites in less accessible areas, while the opposite pattern was observed in North America (Fig. 4; Appendix F). Direct vulnerability, on the other hand, showed consistent negative mean effect size at the continental scale, though only significant in Eurasia (Fig. 4; Appendix F). Distance to settlements was the variable included in this factor for which Continent explained the highest amount of deviance (38\%; Appendix E). The only variable with significantly different effects between continents was Refuge 
habitat within 100ha (Appendix E). Again, we detected a stronger selection towards vegetation providing refuge to wolves in Eurasia compared to North America (mean effect size $=0.73 \pm 0.29$ and $0.09 \pm 0.18$, respectively). Such continental differences were in accordance with the amount of heterogeneity observed in the corresponding random-effects models for factors (Table 2).

Finally, when we evaluated the influence of cofactors related to human activity and the potential for human-wolf conflict (human population density, wolf diet and livestock biomass density) on homesite selection, we found an important contribution of these to the variance observed in Elevation (Appendix G), as well as a significant effect on the mean effect sizes related to different land uses around homesites. Selection for Refuge habitat and avoidance for Agriculture further increased along with human population density (Appendix $\mathrm{G}$ and $\mathrm{H}$ ) and the same pattern was observed for livestock biomass density and wolf diet (Appendix G). Similar patterns were observed when variables were pooled into factors (Appendix I).

\section{Discussion}

Our dataset covered a high proportion of the diversity of ecological contexts in which wolves live, with most of the data used being original (18 out of 26 study areas and 449 out of 728 total homesites in the dataset were primary data). Most of the latitudinal range of the species was represented in our meta-analysis, from the southernmost tips of the species' distribution range in India to the Northwest Territories/Nunavut area of Canada (Fig. 1). On the other hand, a wide range of human impact in the landscape was also covered. Therefore, this study represents the most comprehensive review of the breeding site selection of a large carnivore on a 
global basis so far. The number of studies (26) is within the mean range of sample sizes found in ecological meta-analyses (between 20-30; Koricheva et al., 2013).

Our findings show how homesite selection by wolves is strongly influenced by their perception of risk of interaction with humans. Despite the fact that different local behavioural adaptations to reduce human-related risk at homesites have previously been observed (e.g., Habib and Kumar, 2007; Ahmadi et al., 2014; Iliopoulos et al., 2014), segregation from humans at homesites is a general pattern in wolves regardless of the context-dependent particularities of human pressure. This generalisation reveals that many of such behavioural adaptations are predictable and thus extrapolatable at least at the species level. Minimizing exposure to humans when choosing homesites is fundamental for promoting the survival of pups and other pack members. The observed patterns seem to be common across the entire wolf range regardless of the type of homesite considered, thus supporting the idea of functional similarity between them. Furthermore, similar behavioural responses observed in other large carnivore species (e.g., Linnell et al., 2000, Wilmers et al., 2013, White et al., 2015) suggest that some of the observed patterns in this meta-analysis could be common across the large carnivore guild. Because humans are the main predator of wolves, the homesite selection patterns observed would fit with some of the predictions made for risk effects from humans on wolves (e.g. Creel and Christianson, 2008; Ordiz et al., 2013).

Despite these general patterns, the magnitude of the behavioural response depended largely on the context and the perceived risk of interaction. The importance of the availability of safe places for wolves and the strength of the avoidance of human-made structures increased with human pressure, with a significant distinction in avoidance intensity between continents (Fig. 4). The observed risk-mediated behavioural response suggests that vulnerability should prevail over other factors in 
homesite selection (e.g. soil characteristics, prey availability) because the influence of these factors is observable in areas with low human use (McLoughlin et al., 2004; Ausband et al., 2010; Kaartinen et al., 2010).

Behavioural response of wolves to human-made infrastructures (Fig. 2) seems to vary in relation to road or settlement characteristics; which are related to the level of human activity and its predictability (Thurber et al., 1994; Jędrzejewski et al., 2004; Blanco et al., 2005; Kaartinen et al., 2005; Ahmadi et al., 2014; Iliopoulos et al., 2014; Zimmermann et al., 2014). Wolves are probably able to discriminate between different intensities of traffic and its associated risk (Kaartinen et al., 2005; Whittington et al., 2005). The strength of such behavioural response seems to be stronger where wolves share the landscape more intensely with human activities (Eurasia). For example, in Eurasia, threshold values for settlements and roads from which wolves are absent are remarkably higher compared to North America (Thiel, 1985; Mech et al., 1988; Mladenoff et al., 1995; Woodroffe, 2000; Blanco and Cortés, 2007; Llaneza et al., 2012).

Although it has been reported that wolves are able to persist in agroecosystems in some contexts (Blanco and Cortés, 2007; Agarwala and Kumar, 2009; Ahmadi et al., 2014), wolves generally avoid agricultural lands around homesites. Agricultural lands are usually connected with increased human frequentation and vegetation cover is extremely variable year round (depending on the cultivated crops and harvest periods). Observed increases in the selection of refuge habitat and the avoidance of agricultural land around homesites along a gradient of human pressure (Appendix H) reflect that wolves cope with variations in exposure risk accordingly. The role of open areas remains unclear, and this category probably includes a wide range of habitats differing in protective visual structure at a wolf's height. The 
pastoralist use of these habitats in some areas can also have a significant influence on homesite selection (Habib and Kumar 2007), without an accurate characterisation in our analyses.

Our results suggest a hierarchical habitat selection process by which wolves compensate for higher exposure risk within their territories via stronger selection against this risk at homesites (see Basille et al., 2013 for a similar process in Eurasian lynx Lynx lynx;). Although wolves coexisting with humans are expected to be more tolerant of humans (Mech and Boitani, 2003), the strength of risk avoidance at different orders of selection (Johnson, 1980) may be dependent on the history of coexistence and persecution. In this regard, stronger human avoidance at the first and second selection orders (occupancy and territory) in North America (Mladenoff et al., 1995; Woodroffe, 2000; Wydeven et al., 2001; Oakleaf et al., 2006) could explain the lower magnitude of the response observed at the third selection order (homesites). On the contrary, in Eurasia, a higher tolerance of human-made structures at lower selection orders (Woodroffe, 2000; Jędrzejewski et al., 2004; Blanco et al., 2005; Llaneza et al., 2012), may force wolves to be more cautious at critical places within their territories, such as homesites. Continental patterns have been previously exemplified by divergent adaptations and tolerance thresholds in large carnivores and ungulates (Woodroffe, 2000; Sand et al., 2006). Differences in life-history traits associated with a different history of persecution have been reported for brown bears (Ursus arctos) (Zedrosser et al., 2011), but no such large-scale (continental level) differences have been previously reported regarding behavioural adaptations in large carnivores.

Wolves in Eurasia are more prone to inhabit cultural landscapes and share their territories with humans in a closer proximity than in North America (Chapron et 
al., 2014). A social and political willingness for coexistence has been suggested to be an important factor that may shape intrinsic behavioural characteristics (Chapron et al., 2014). The stronger selection of homesites at inaccessible places (e.g. due to Topography) in Eurasia compared to North America appears to be a behavioural adaptation of wolves to persist in human-dominated landscapes, contributing to the coexistence pattern observed in Europe (Chapron et al., 2014). Wolves occurring in areas with low human population density have greater availability of valley bottoms and lower slopes compared to wolves in human-dominated landscapes, where agricultural land and urban development dominate (Llaneza et al., 2012). Milder climate conditions, increased water availability and/or prey abundance could partly explain the preference for valley bottoms in areas with low human population density (Ausband et al., 2010).

Historically, the intensity of large carnivore persecution in Eurasia increased in parallel with the expansion of livestock husbandry after domestication around 11 000 yrs BP (Vigne, 2011). As a consequence, Eurasian large carnivore populations have been subjected to human persecution for millennia, and the effectiveness of techniques to kill wolves has become gradually more sophisticated over time. On the other hand, North American large carnivore populations were severely depleted shortly after European settlers expanded westwards and intensive persecution began during the $18^{\text {th }}$ century (Frank and Woodroffe, 2001). Thus, a gradual long-term coadaptation between persecution techniques and anti-predator behaviour in Eurasia compared to North America may be the mechanism behind the observed continental pattern. Livestock biomass density and livestock as the primary component of the wolf diet were positively correlated with selection towards refuge vegetation and likely reflect the adaptive behaviour of wolves to be more secretive in areas where 
livestock represent the primary prey item of wolves and where human animosity is presumed to be higher.

Despite the renowned habitat plasticity of wolves (Mech and Boitani, 2003), we have identified strict habitat requirements for wolves at a small spatial scale during a critical period for the species. Large carnivore conservation is often hindered by the remarkable spatial requirements and the need to preserve large areas of suitable habitats (Weber and Rabinowitz, 1996; Woodroffe and Ginsberg, 1998; but see Chapron et al., 2014; López-Bao et al., 2015). Although many large carnivores do not necessarily require such large-scale habitat preservation, the issue of habitat protection for these species should not be disregarded but rather identified at the proper scale. Habitat selection at levels (orders) below occupancy and territory, along with the interaction with human-related risks should be regarded in the management and conservation of large carnivores in human-dominated landscapes.

Wolves repeatedly using the same homesites and vocalising in their vicinity are vulnerable to humans, especially those actively searching for litters or aiming to eradicate entire wolf packs. Although the protection of the breeding sites of large carnivores is mandatory in some legal contexts (e.g. European Union and the Council of Europe), such as for populations listed in Annex II of the EU Habitats Directive 92/43/EEC of 1992, the enforcement of their effective protection is still lacking in many areas. When management and conservation goals aim to preserve large carnivores in human-dominated landscapes, providing insights on the general patterns of breeding site selection patterns is a valuable tool for guiding decision-making processes. In this case, we recommend that managers should be focused on providing shelter from human interference in the small portions of land that fulfill the 
characteristics of the places that wolves in particular and large carnivores in general select as breeding sites, in order to encourage their persistence.

\section{Acknowledgments}

We are in debt with all the administrative, logistical and funding support from the Picos de Europa National Park and the Regional Government of Galicia (Spain), the Spanish Ministry of Economy and Competitiveness (SEV-2012-0262), the Government of the Northwest Territories and the University of Northern British Columbia (Canada), the U.S.A. National Park Service, the Alaska Department of Fish and Game, the U.S.A. Department of Agriculture (USDA) Forest Service, the Wisconsin Departments of Natural Resources and Transportation, the University of Wisconsin-Stevens Point, the Government of India, the Regional Government of Maharastra (India), the Progetto Lupo Piemonte (Italy), the European Union and the Slovenian Ministry of Agriculture and Environment (LIFE08/NAT/SLO/000244), the Mexican wolf recovery program (partnership: USFWS, AGFD, WMAT, USDA Forest Service, and the USDA Animal and Plant Health Inspection Services-Wildlife Services, and several participating counties). We thank John Burch for facilitating the use of the data from Yukon-Charley Rivers National Preserve. JVLB was supported by the Spanish Ministry of Economy and Competitiveness (JCI-2012-13066). MK was supported by Slovenian Research Agency (ARRS, P4-0059). We are especially thankful to Ed Bangs and David Mech for their help in obtaining data from North America. We thank Alon Reichmann, Amitzur Boldo Michal Ucko, Reuven Hefner, Mónia Nakamura and Vicente Palacios and SloWolf project volunteers for doing hard fieldwork locating homesites. This is scientific paper no. XX from the Iberian Wolf Research Team (IWRT). The findings and conclusions of this article are those of the 
authors and do not necessarily represent the views of the U.S. Fish and Wildlife Service or other agencies.

\section{References}

Abay, G.Y., Bauer, H., Gebrihiwot, K., Deckers, J., 2011. Peri-urban spotted hyena (Crocuta crocuta) in northern Ethiopia, diet, economic impact, and abundance. Eur. J. Wildlife Res. 57, 759-765.

Agarwala, M., Kumar, S., 2009. Wolves in agricultural landscapes in western India. Tropical Resources, Bulletin of the Yale Tropical Resources Institute 28, 4853.

Ahmadi, M., López-Bao, J.V., Kaboli, M., 2014. Spatial heterogeneity in human activities favours persistence of wolves in agroecosystems. PLoS ONE 9, e108080.

Athreya, V., Odden, M., Linnell, J.D.C., Krishnaswamy, J., Karanth, U. 2013. Big cats in our backyards, persistence of large carnivores in a human dominated landscape in India. PLoS ONE 8, e57872.

Ausband, D.E., Mitchell, M.S., Doherty, K., Zager, P., Mack, C.M., Holyan, J., 2010. Surveying predicted rendezvous sites to monitor gray wolf populations. Journal of Wildlife Management 74, 1043-1049.

Basille, M., Van Moorter, B., Herfindal, I., Martin, J., Linnell, J.D.C., Odden, J., Andersen, R., Gaillard, J.M., 2013 Selecting habitat to survive, the impact of road density on survival in a large carnivore. PLoS ONE 8, e65493.

Blanco, J.C., Cortés, Y., Virgós, E, 2005 Wolf response to two kinds of barriers in an agricultural habitat in Spain. Canadian Journal of Zoology 83, 312-323.

Blanco, J.C., Cortés, Y., 2007. Dispersal patterns, social structure and mortality of wolves living in agricultural habitats in Spain. Journal of Zoology 273, 114-124. 
Capitani, C., Mattioli, L., Avanzinelli, E., Gazzola, A., Lamberti, P., Mauri, L., Scandura, M., Viviani, A., Apollonio, M., 2006. Selection of rendezvous sites and reuse of pup raising areas among wolves Canis lupus of north-eastern Apennines, Italy. Acta Theriologica 51, 395-404.

Carbyn, L.N., Oosenbrug, S.M., Anions, D.W., 1993. Wolves, bison, and the dynamics related to the Peace-Athabasca delta in the Canada's Wood Buffalo National Park. Circumpolar Research Series 4, Canadian Circumpolar Institute, University of Alberta, Edmonton.

Chapron, G., Kaczensky, P., Linnell, J.D.C., von Arx, M., Huber, D., Andrén, H., López-Bao, J.V., Adamec, M., Álvares, F., Anders, O., Balčiauskas, L., Balys, V., Bedő, P., Bego, F., Blanco, J.C., Breitenmoser, U., Brøseth, H., Bufka, L., Bunikyte, R., Ciucci, P., Dutsov, A., Engleder, T., Fuxjäger, C., Groff, C., Holmala, K., Hoxha, B., Iliopoulos, Y., Ionescu, O., Jeremić, J., Jerina, K., Kluth, G., Knauer, F., Kojola, I., Kos, I., Krofel, M., Kubala, J., Kunovac, S., Kusak, J., Kutal, M., Liberg, O., Majić, A., Männil, P., Manz, R., Marboutin, E., Marucco, F., Melovski, D., Mersini, K., Mertzanis, Y., Mysłajek, R.W., Nowak, S., Odden, J., Ozolins, J., Palomero, G., Paunović, M., Persson, J., Potočnik, H., Quenette, P.Y., Rauer, G., Reinhardt, I., Rigg, R., Ryser, A., Salvatori, V., Skrbinšek, T., Stojanov, A., Swenson, J.E., Szemethy, L., Trajçe, A., Tsingarska-Sedefcheva, E., Váňa, M., Veeroja, R., Wabakken, P., Wölfl, M., Wölfl, S., Zimmermann, F., Zlatanova, D., Boitani, L., 2014. Recovery of large carnivores in Europe's modern human-dominated landscapes. Science 346, 15171519.

Creel, S., Christianson, D.A., 2008. Relationships between direct predation and risk effects. Trends Ecol. Evol. 23, 194-201. 
Del Re, A.C., 2013. Compute.es, Compute effect sizes. R package version 0.2-2. http, //cran.r-project.org/web/packages/compute.es

Frank, L.G., Woodroffe, R., 2001. Behaviour of carnivores in exploited and controlled populations. Carnivore conservation (ed. by Gittleman, J.L., Funk, S.M., Macdonald, D.W., and Wayne, R.K.), pp.419-442. Conservation Biology Series, Cambridge University Press, Cambridge.

Fuller, T.K., Sievert, P.R., 2001. Carnivore demography and the consequences of changes in prey availability, in: Gittleman, J.L., Funk, S.M., Macdonald D., Wayne, R.K. (Eds.), Carnivore conservation. Cambridge University Press, Cambridge, UK, pp. $163-178$.

Habib, B., Kumar, S., 2007. Den shifting by wolves in semi-wild landscapes in the Deccan Plateau, Maharashtra, India. Journal of Zoology 272, 259-265.

Iliopoulos, Y., Youlatos, D. Sgardelis, S., 2014. Wolf pack rendezvous site selection in Greece is mainly affected by anthropogenic landscape features. European Journal of Wildlife Research 60, 23-34.

Jędrzejewski, W., Niedziałkowska, M., Nowak, S., Jędrzejewska, B., 2004. Habitat variables associated with wolf (Canis lupus) distribution and abundance in northern Poland. Diversity and Distributions 10, 225-233.

Johnson, D.H., 1980. The comparison of usage and availability measurements for evaluating resource preference. Ecology 61, 65-71.

Joslin, P.W.B., 1967. Movements and homesites of timber wolves in Algonquin Park. American Zoologist 7, 279-288.

Kaartinen, S., Kojola, I., Colpaert, C., 2005. Finnish wolves avoid roads and settlements. Annales Zoologici Fennici 42, 523-532 
Kaartinen, S., Luoto, M., Kojola, I., 2010. Selection of den sites by wolves in boreal forests in Finland. Journal of Zoology 281, 99-104.

Koricheva, J., Gurevitch, J., Mengersen, K. (Eds.), 2013. Handbook of metaanalysis in ecology and evolution. Princeton University Press, Princeton.

Lesmerises, F., Dussault, C., Saint-Laurent, M.H., 2013. Major roadwork impacts the space use behaviour of gray wolf. Landscape and Urban Planning 112, 18-25.

Levin, S.A., 1992. The problem of pattern and scale in ecology. Ecology 73, 19431967.

Linnell, J.D.C., Swenson, J.E., Andersen, R., Barnes, B., 2000. How vulnerable are denning bears to disturbance? Wildlife Society Bulletin 28, 400-413.

Linnell, J.D.C., Odden, J., Mertens, A., 2012. Mitigation methods for conflicts associated with carnivore depredation on livestock. Carnivore ecology and conservation: A handbook of techniques (ed. by Boitani, L. and Powell, R.A.) pp. 314-332. Oxford University Press, Oxford.

Llaneza, L., López-Bao, J.V., Sazatornil, V., 2012. Insights into wolf presence in human-dominated landscapes: the relative role of food availability, humans and landscape attributes. Diversity and Distributions 18, 459-469.

Llaneza, L., García, E.J., López-Bao, J.V., 2014. Intensity of territorial marking predicts wolf reproduction: Implications for wolf monitoring. PLoS ONE 9, e93015. López-Bao, J.V., Sazatornil, V., Llaneza, L., Rodríguez, A., 2013. Indirect effects on heathland conservation and wolf persistence of contradictory policies that threaten traditional free-ranging horse husbandry. Conservation Letters 6, 448-455.

López-Bao, J.V., Kaczensky, P., Linnell, J.D., Boitani, L., Chapron, G., 2015. Carnivore coexistence: Wilderness not required. Science 348, 871-872. 
McLoughlin, P.D., Walton, L.R., Cluff, H.D., Paquet, P.C., Ramsay, M.A., 2004.

Hierarchical habitat selection by tundra wolves. Journal of Mammalogy 85, 576-580.

Mech, L.D., 1970. The wolf, the ecology and behavior of an endangered species. Natural History Press, Doubleday Publishing Co., New York.

Mech, L. D., 1989. Wolf population survival in an area of high road density. American Midland Naturalist 121, 387-389.

Mech, L.D., Boitani, L. (Eds.), 2003. Wolves, behavior, ecology, and conservation. The University of Chicago Press, Chicago.

Mech, L.D., Fritts, S.H., Radde, G., Paul, W.J., 1988. Wolf distribution in Minnesota relative to road density. Wildlife Society Bulletin 16, 85-88.

Mladenoff, D., Sickley, T.A., Haight, R.G., Wydeven, A.P., 1995. A regional landscape analysis and prediction of favourable gray wolf habitat in the northern great lakes region. Conservation Biology 9, 279-294.

Oakleaf, J.K., Murray, D.L., Oakleaf, J.R., Bangs, E.E., Mack, C.M., Smith, D.W., Fontaine, J.A., Jimenez, M.A., Meier, T.J., Niemeyer, C.C., 2006. Habitat selection by recolonizing wolves in the northern Rocky Mountains of the United States. Journal of Wildlife Management 70, 554-563.

Ordiz, A., Bischof, R., Swenson, J.E., 2013. Saving large carnivores, but losing the apex predator?. Biological Conservation 168, 128-133.

Packer, C., Loveridge, A., Canney, S., Caro, T., Garnett, S.T., Pfeifer, M., Zander, K.K., Swanson, A., MacNulty, D., Balme, G., Bauer, H., Begg, C.M., Begg, K.S., Bhalla, S., Bissett, C., Bodasing, T., Brink, H., Burger, A., Burton, A.C., Clegg, B., Dell, S., Delsink, A., Dickerson, T., Dloniak, S.M., Druce, D., Frank, L., Funston, P., Gichohi, N., Groom, R., Hanekom, C., Heath, B., Hunter, L., DeIongh, H.H., Joubert, C.J., Kasiki, S.M., Kissui, B., Knocker, W., Leathem, 
B., Lindsey, P.A., Maclennan, S.D., McNutt, J.W., Miller, S.M., Naylor, S., Nel,

P., Ng'weno, C., Nicholls, K., Ogutu, J.O. and Okot-Omoya, E., Patterson, B.D.,

Plumptre, A., Salerno, J., Skinner, K., Slotow, R., Sogbohossou, E.A., Stratford, K.J.,

Winterbach, C., Winterbach, H., Polasky, S., 2013. Conserving large carnivores:

Dollars and fence. Ecology Letters 16, 635-641.

Person, D.K., Russell, A.L., 2009. Reproduction and den site selection by wolves in a disturbed landscape. Northwest Science 83, 211-224.

R Core Team., 2014. R, a language and environment for statistical computing. R Foundation for Statistical Computing, Vienna. www.R-project.org/.

Ruprecht, J.S., Ausband, D.E., Mitchell, M.S., Garton, E.O., Zager, P., 2012.

Homesite attendance based on sex, reproductive status and number of helpers in gray wolf packs. Journal of Mammalogy 93, 1001-1005.

Sand, H., Wikenros, C., Wabakken, P., Liberg, O., 2006. Cross-continental differences in patterns of predation, will naive moose in Scandinavia ever learn?. Proceedings of the Royal Society of London B 273, 1421-1427.

Sappington, J.M., Longshore, K.M., Thompson, D.B., 2007. Quantifying Landscape Ruggedness for Animal Habitat Analysis: A Case Study Using Bighorn Sheep in the Mojave Desert. Journal of Wildlife Management 71:1419-1426.

Theuerkauf, J., Rouys, S., Jędrzejewski, W., 2003. Selection of dens, rendezvous and resting sites by wolves in the Bialowieza Forest, Poland. Canadian Journal of Zoology 81, 163-167.

Thiel, R.P., 1985. The relationship between road densities and habitat suitability in Wisconsin. American Midland Naturalist 113, 404-407.

Thiel, R.P., Merrill, S., Mech L.D., 1998. Tolerance by denning wolves, Canis lupus, to human disturbance. Canadian Field Naturalist 122, 340-342. 
Thurber, J.M., Peterson, R.O., Drummer, T.D., Thomasma, S.A., 1994. Gray wolf response to refuge boundaries and roads in Alaska. Wildlife Society Bulletin 22, 6168.

Viechtbauer, W., 2005. Bias and efficiency of meta-analytic variance estimators in the random-effects model. Journal of Educational and Behavioral Statistics 30, 261293.

Viechtbauer, W., 2010. Conducting meta-analyses in R with the metafor package. Journal of Statistical Software 36, 1-48.

Vigne, J.D., 2011. The origins of animal domestication and husbandry, A major change in the history of humanity and the biosphere. Comptes Rendus Biologies 334, $171-181$

Weber, W., Rabinowitz, A., 1996. A global perspective on large carnivore conservation. Conservation Biology 10, 1046-1054.

White, S., Briers, R. A., Bouyer, Y., Odden, J., Linnell, J. D. C., 2015. Eurasian lynx natal den site and maternal home-range selection in multi-use landscapes of Norway. Journal of Zoology 297, 87-98.

Wilmers, C.C., Wang, Y., Nickel, B., Houghtaling, P., Shakeri, Y., Allen, M.L., Kermish-Wells, J., Yovovich, V., Williams, T., 2013. Scale dependent behavioral responses to human development by a large predator, the Puma. PLoS ONE 8, e60590.

Whittington, J., St. Clair, C.C., Mercer, G., 2005. Spatial responses of wolves to roads and trails in mountain valleys. Ecological Applications 15, 543-553.

Woodroffe, R., 2000. Predators and people, using human densities to interpret declines of large carnivores. Animal Conservation 3, 165-173. 
Woodroffe, R., Ginsberg, J.R., 1998. Edge effects and the extinction of populations inside protected areas. Science 280, 2126-2128.

Woodroffe, R., Frank, L.G., Lindsey, P.A., Ranah, S.M.K., Romañach S., 2007. Livestock husbandry as a tool for carnivore conservation in Africa's community rangelands: A case-control study. Vertebrate Conservation and Biodiversity 5, 419434.

Wydeven, A.P., Mladenoff, D.J., Sickley, T.A., Kohn, B.E., Thiel, R.P., Hansen, J.L., 2001. Road density as a factor in habitat selection by wolves and other carnivores in the Great Lakes Region. Endangered Species Update 18, 110-114.

Zedrosser, A., Steyaert, S.M.J.G., Gossow, H., Swenson, J.E., 2011. Brown bear conservation and the ghost of persecution past. Biological Conservation 144, 2163 2170.

Zimmermann, B., Nelson, L., Wabakken, P., Sand, H., Liberg, O., 2014. Behavioral responses of wolves to roads: Scale-dependent ambivalence. Behavioral Ecology 25, 1353-1364. 
Table 1. Description of the variables used in the meta-analysis analyzing homesite selection patterns by wolves in relation to human-related risk.

\begin{tabular}{|c|c|c|c|}
\hline Scale $^{1}$ & Variable & Factor & Description \\
\hline 0 & Distance to Settlements & $\begin{array}{l}\text { Direct } \\
\text { Vulnerability }\end{array}$ & $\begin{array}{l}\text { Distance to the nearest human settlement (m), including villages } \\
\text { but also isolated constructions and facilities such as farms, } \\
\text { ranches, mine camps, park's visitor centres etc. composed by 2-9 } \\
\text { buildings. }\end{array}$ \\
\hline 0 & Distance to Villages & $\begin{array}{l}\text { Direct } \\
\text { Vulnerability }\end{array}$ & $\begin{array}{l}\text { Distance to the nearest village }(\mathrm{m}) \text { (aggregation of } 10 \text { or more } \\
\text { buildings, or when explicitly considered as village in the original } \\
\text { study or dataset). }\end{array}$ \\
\hline 0 & Distance to Roads & $\begin{array}{l}\text { Direct } \\
\text { Vulnerability }\end{array}$ & $\begin{array}{l}\text { Distance to the nearest road of any type (m), including gravel and } \\
\text { forestry roads. When able to be discriminated, roads with evident } \\
\text { signs of abandonment were not considered. }\end{array}$ \\
\hline 0 & Distance to Main Roads & $\begin{array}{l}\text { Direct } \\
\text { Vulnerability }\end{array}$ & $\begin{array}{l}\text { Distance to the nearest first or second-class road (m), usually } \\
\text { paved roads but depending on the local context some unpaved } \\
\text { roads were also included when represented the main transportation } \\
\text { infrastructure connecting } 2 \text { villages (e.g. India-Maharashtra). }\end{array}$ \\
\hline 0 & Elevation & Topography & Elevation above sea level (m). \\
\hline 1 & Terrain Ruggedness & Topography & $\begin{array}{l}\text { Vector Ruggedness Measure (VRM index) calculated according to } \\
\text { Sappington et al. (2007). }\end{array}$ \\
\hline 2 & Terrain Ruggedness & - & VRM index calculated according to Sappington et al. (2007). \\
\hline 0 & Slope & Topography & $\begin{array}{l}\text { Slope (degrees) obtained from Digital Elevation Model (DEM) } \\
\text { surface analysis }\end{array}$ \\
\hline 1 & Refuge habitat & - & $\begin{array}{l}\text { Area within buffer around site occupied by forests and scrubland } \\
\text { (except creeping scrubs) }\end{array}$ \\
\hline 2 & Refuge habitat & - & $\begin{array}{l}\text { Area within buffer around site occupied by forests and scrubland } \\
\text { (except creeping scrubs) }\end{array}$ \\
\hline 1 & Open Areas & - & $\begin{array}{l}\text { Area within buffer around site occupied by land uses } \\
\text { corresponding to bare soil or open vegetation such as natural } \\
\text { grasslands, pastures, moors, tundra, dwarf scrubland, etc. }\end{array}$ \\
\hline 2 & Open Areas & - & $\begin{array}{l}\text { Area within buffer around site occupied by land uses } \\
\text { corresponding to bare soil or open vegetation such as natural } \\
\text { grasslands, pastures, moors, tundra, dwarf scrubland, etc. }\end{array}$ \\
\hline 1 & Agriculture & - & Area within buffer around site occupied by agricultural land. \\
\hline 2 & Agriculture & - & Area within buffer around site occupied by agricultural land. \\
\hline 1 & Urban & $\begin{array}{l}\text { Direct } \\
\text { Vulnerability }\end{array}$ & $\begin{array}{l}\text { Area within buffer around site occupied by residential, industrial } \\
\text { or commercial uses. }\end{array}$ \\
\hline 2 & Urban & - & $\begin{array}{l}\text { Area within buffer around site occupied by residential, industrial } \\
\text { or commercial uses. }\end{array}$ \\
\hline
\end{tabular}

${ }^{1} 0$ : Scale-independent; $1: \leq 100$ ha; $2: \leq 900$ ha 
Table 2: Sample size, total heterogeneity $\left(T^{2}\right)$ and heterogeneity among true effects $\left(I^{2}\right)$ of random-effects models of joint (den and rendezvous) homesite dataset.

\begin{tabular}{lccc}
\hline VARIABLE/FACTOR & $\mathrm{n}$ & $T^{2}(\mathrm{SE})$ & $I^{2}(\%)$ \\
\hline Distance to Main roads & 16 & $0.08(0.05)$ & 61.0 \\
Distance to Roads & 22 & $0.09(0.09)$ & 62.1 \\
Distance to Villages & 13 & $0.28(0.14)$ & 83.6 \\
Distance to Settlements & 17 & $0.20(0.10)$ & 76.5 \\
Elevation & 23 & $0.28(0.10)$ & 83.1 \\
Slope & 22 & $0.23(0.09)$ & 79.7 \\
Ruggedness 100 ha & 17 & $0.06(0.04)$ & 51.9 \\
Ruggedness 900 ha & 17 & $0.10(0.06)$ & 62.6 \\
Agriculture 100 ha & 11 & $0.17(0.10)$ & 75.9 \\
Agriculture 900 ha & 10 & $0.10(0.07)$ & 65.9 \\
Open Areas 100 ha & 17 & $0.04(0.04)$ & 41.1 \\
Open Areas 900 ha & 17 & $0.04(0.03)$ & 37.6 \\
Refuge habitat 100 ha & 18 & $0.20(0.09)$ & 77.4 \\
Refuge habitat 900 ha & 16 & $0.14(0.07)$ & 70.4 \\
Urban 100 ha & 10 & $0.00(0.02)$ & 0.3 \\
Urban 900 ha & 11 & $0.04(0.04)$ & 42.0 \\
& & & \\
Direct Vulnerability (factor) & 50 & $0.13(0.04)$ & 70.3 \\
Topography (factor) & 62 & $0.19(0.05)$ & 77.0 \\
& & &
\end{tabular}




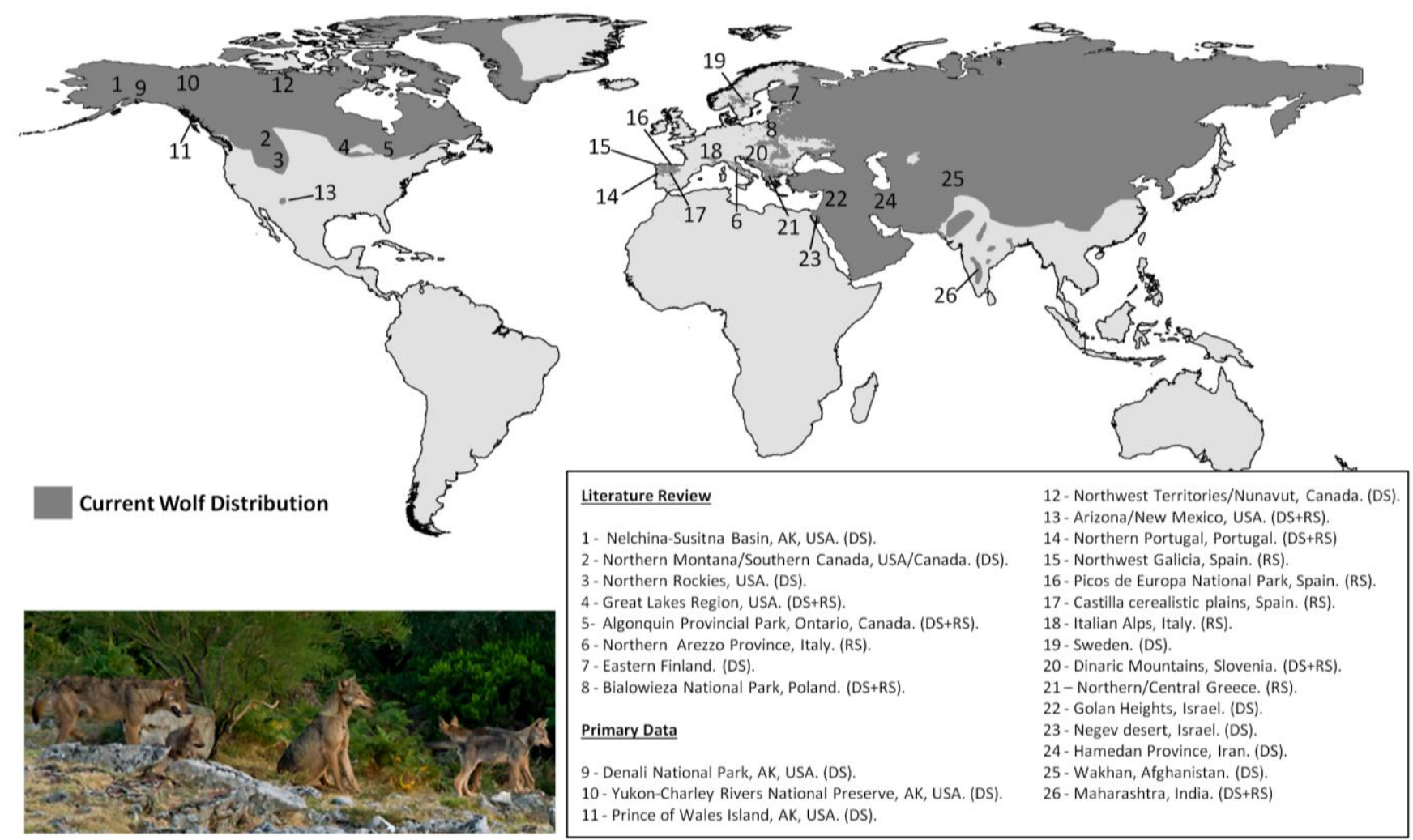

Figure 1. Study areas included in the meta-analysis on global patterns of homesite selection by wolves. (Wolf distribution: IUCN (International Union for Conservation of Nature) 2010. Canis lupus. The IUCN Red List of Threatened Species. Version 2014.3; $\mathrm{DS}=$ den sites data; $\mathrm{RS}=$ rendezvous sites data) (Photo credit: ${ }^{\circ}$ Artur Oliveira/CIBIO). 
Distance to Main Roads

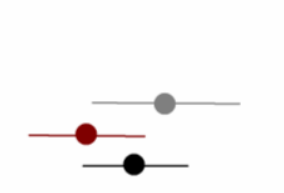

Distance to Roads

Distance to Villages

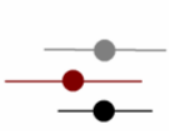

Distance to Settlements

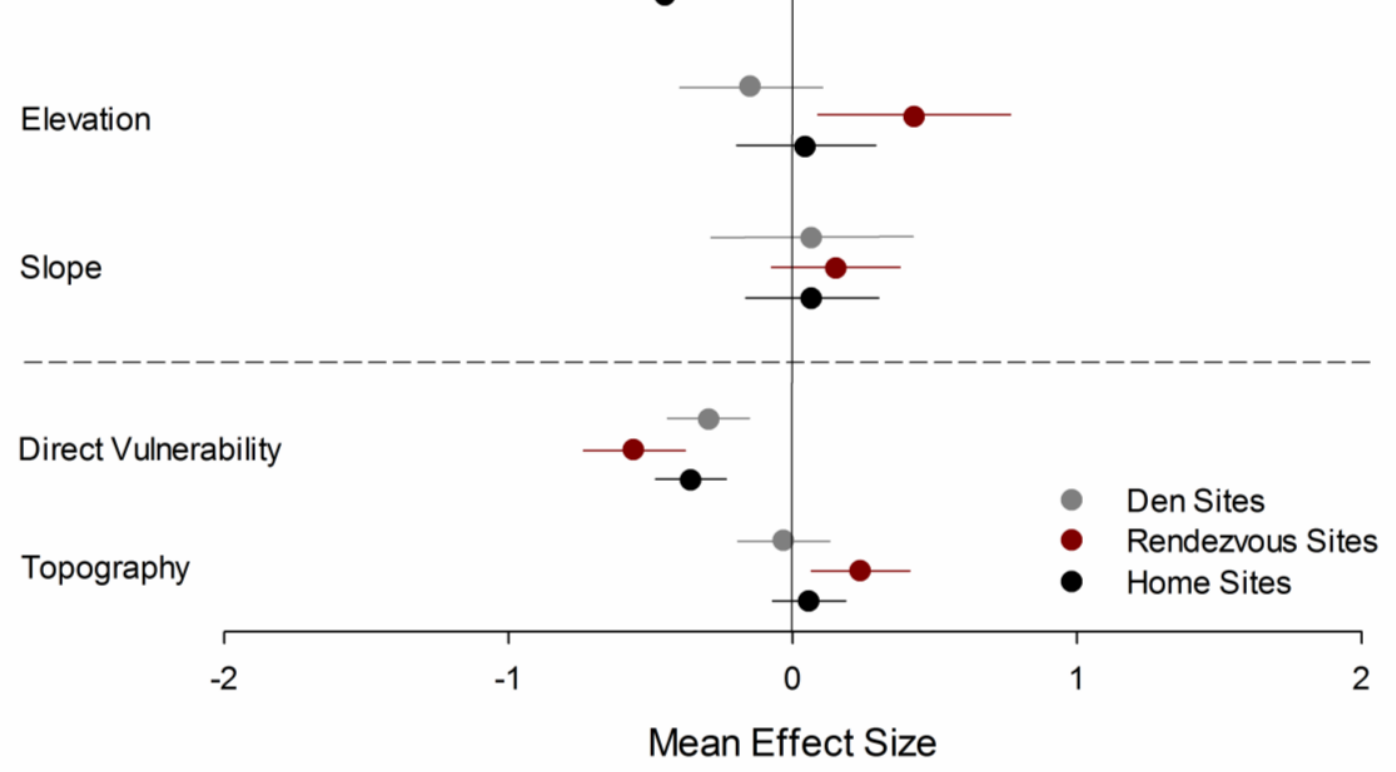

Figure 2. Results of the meta-analysis on homesite selection patterns by wolves regarding scale-independent variables (above dashed line) and factors (below dashed line). The summary effect size of every variable/factor (points) across study areas and $\pm 95 \%$ confidence intervals (lines) are shown. Summary effect sizes are shown for homesites, den and rendezvous sites. Confidence intervals containing zero were interpreted as non-significant and no general effect was considered to be plausible regarding the corresponding variable. Sign of distance-based variables has been shifted for better representation (i.e. negative values represent avoidance). 


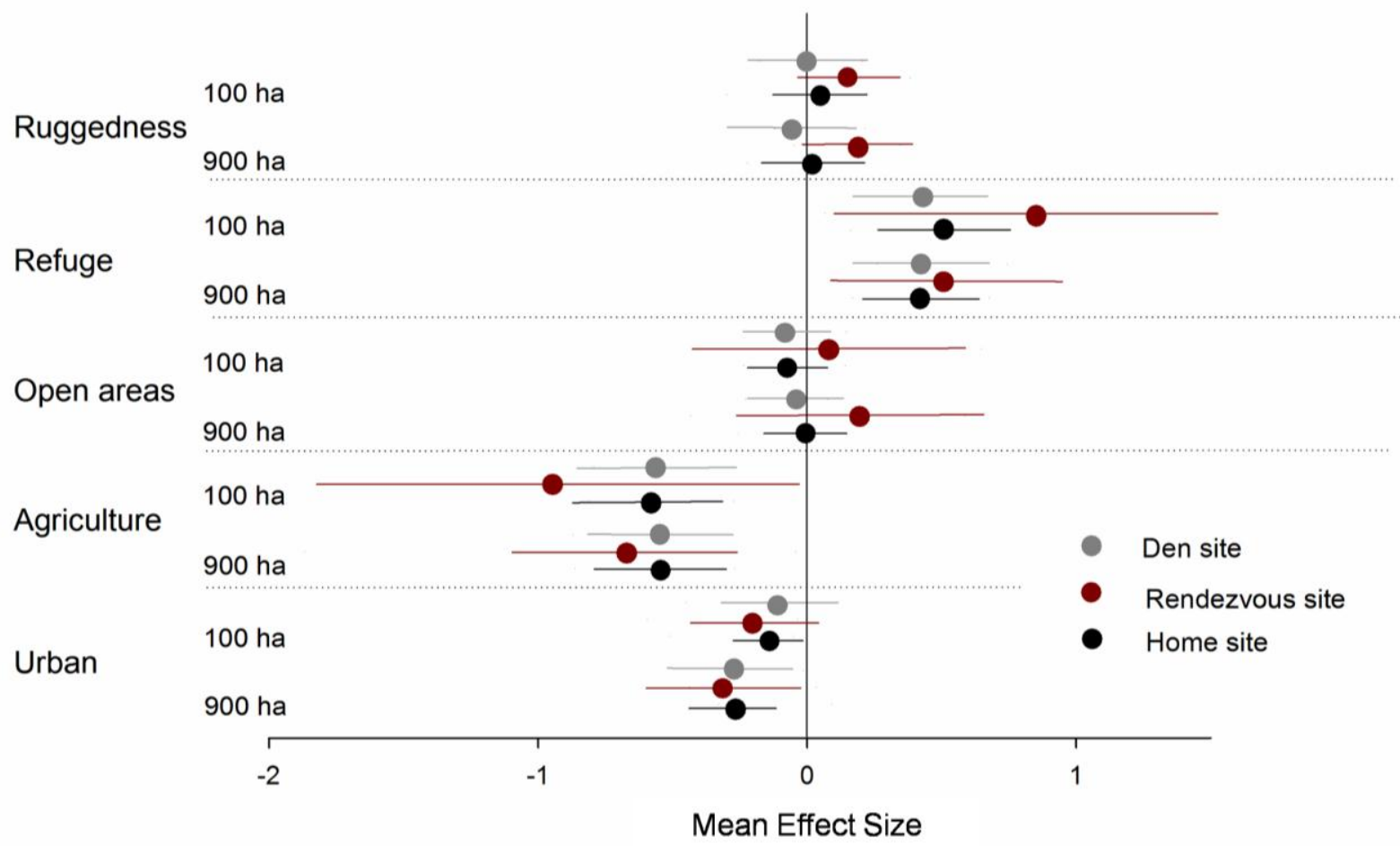

Figure 3. Results of the meta-analysis of homesite selection regarding variables measured at two spatial resolutions, 100 and 900 ha around homesites. The summary effect size for every variable/factor (points) across study areas and $\pm 95 \%$ confidence intervals (lines) are shown. Summary effect sizes are shown for homesites, den and rendezvous sites. Confidence intervals containing zero were interpreted as nonsignificant and no general effect was considered to be plausible regarding the corresponding variable. 


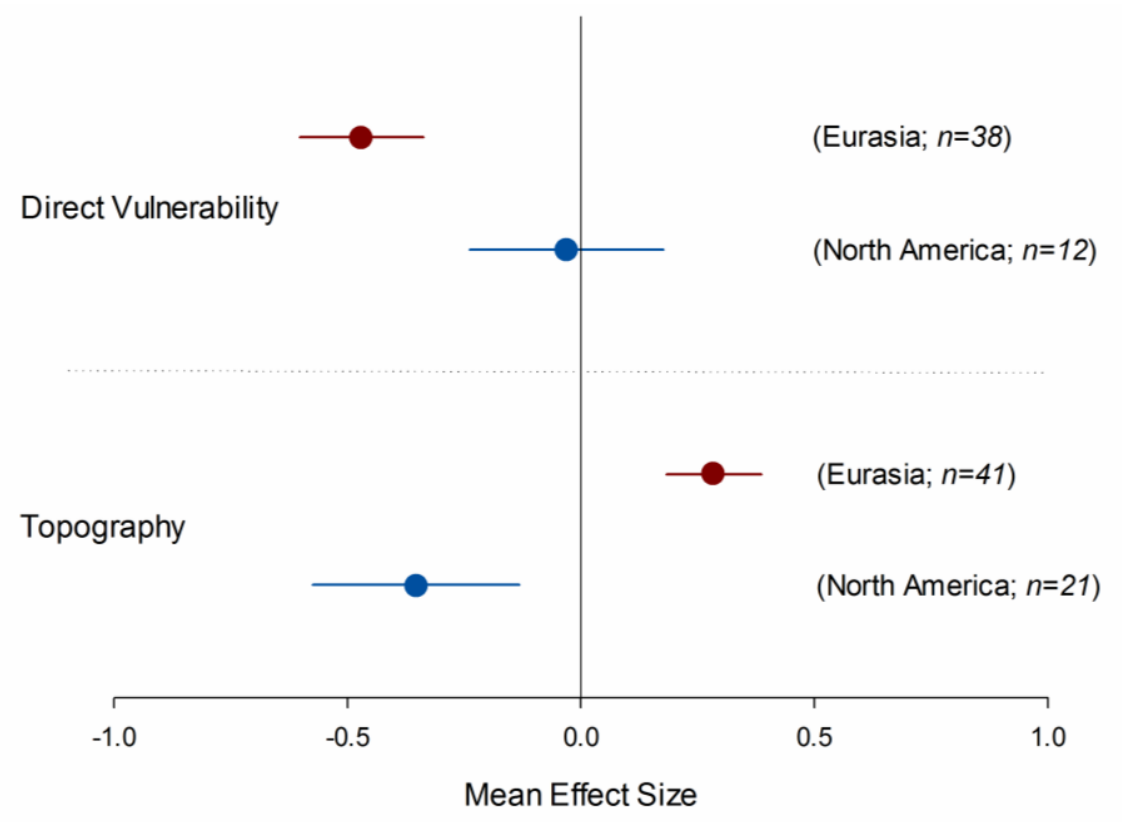

Figure 4: Comparison between the continents of the mean effect size (points) and \pm $95 \%$ confidence intervals (lines) of factors grouping variables associated with Direct Vulnerability and Topography (see methods for details). All homesites pooled. 